\title{
MEASURING POTENCY OF BTK FORMULATIONS AGAINST PAINTED APPLE MOTH (TEIA ANARTOIDES) LARVAE USING AN ARTIFICIAL DIET BIOASSAY
}

\author{
B.A. GRESHAM, K.D. STEELE and S.F. GOUS \\ Forest Research, Private Bag 3020, Rotorua, New Zealand \\ Corresponding author: kevin.steele@forestresearch.co.nz.
}

\begin{abstract}
A number of formulations of Btk (Bacillus thuringiensis kurstaki) are available in New Zealand for control of lepidopterous species. The efficacy of these formulations is often tested subsequent to spraying, using exposed host foliage in larval bioassays. To provide additional quality assurance, the standard American potency bioassay has been adapted by using third instar Teia anartoides larvae, a relevant pest species, and Dipel DF (a dry Btk formulation with a long and stable shelf life) as reference potency for comparison. A series of different batches of a Btk formulation were incorporated into artificial diet at rates known to be sublethal and in the region of $\mathrm{LC}_{50}$. Larvae were placed on to the diet and mortality assessed at 4 and 7 days. Control larvae were reared on diet without Btk. All formulation batches produced similar results to the reference (Dipel DF) with the exception of the oldest batch that had slightly lower potency. Potency testing using artificial diet can provide quality assurance for different batches and, combined with efficacy testing on host foliage, improve the auditing of spraying operations.
\end{abstract}

\section{ERADICATION OF THE SOUTHERN SALTMARSH MOSQUITO, OCHLEROTATUS CAMPTORHYNCHUS, FROM NAPIER}

\author{
S.J. GARNER, M. DISBURY, S.J. CRARER and R.P. CANE \\ New Zealand BioSecure, P.O. Box 650, Napier, New Zealand \\ Corresponding author: steveg@nzbiosecure.net.nz.
}

The Australian southern saltmarsh mosquito, Ochlerotatus camptorhynchus Thomson (Diptera: Culicidae), was first discovered in Napier in December 1998. Adult females of this species are aggressive biters and are a significant vector of the Ross River virus, a debilitating arbovirus affecting humans and horses. The arrival of this species posed a significant health and nuisance threat to our community and the tourism industry. In April 1999, the Ministry of Health decided to attempt an eradication. A surveillance team commenced sampling and trapping to ascertain the extent of the incursion and this information was used to direct the treatment programme. Treatments commenced in January 1999. The biological larvicide Bacillus thuringiensis var. israelensis (B.t.i.) was utilised for the first eight months and was then replaced by formulations of the juvenile hormone analogue $S$-methoprene, imported from the USA. Helicopter, quad bike and backpack applications were used to apply the products. Treatments, trapping and surveillance were monitored using a Global Information Systems (GIS) computer software application. The last adult was trapped April 2000, the last larva collected July 2000, and treatments ceased April 2001. The team continued surveillance activities until eradication at the Napier site was formally achieved in July 2002. 